\title{
Depolarization Increases Vasoactive Intestinal Peptide- and Substance P-like Immunoreactivities in Cultured Neonatal and Adult Sympathetic Neurons
}

\author{
Y. Sun, M. S. Rao, S. C. Landis, and R. E. Zigmond \\ Department of Neurosciences, Case Western Reserve University, School of Medicine, Cleveland, Ohio 44106
}

\begin{abstract}
Depolarization has been shown to alter the biosynthesis of a number of neurotransmitters and neuromodulators. In the rat superior cervical ganglion (SCG), for example, depolarization has been reported to increase catecholamine biosynthesis and to decrease the level of substance $P$. We have recently found that, although the level of vasoactive intestinal peptide (VIP)-like immunoreactivity (IR) is normally low in the SCG, it increases significantly $48 \mathrm{hr}$ after adult ganglia are deafferented in situ or placed in organ culture. Both manipulations decrease electrical activity of postganglionic neurons. To determine whether the increases in ganglionic VIP-IR could be a consequence of decreased depolarization of sympathetic neurons, the effect of depolarization on the expression of VIP-IR was examined in organ cultures of neonatal and adult SCG. Depolarization with elevated $K^{+}(30$ $\mathrm{mM})$ or veratridine $(1.5 \mu \mathrm{M})$ amplified, rather than blocked, the increases in VIP-IR content seen after $24 \mathrm{hr}$. Further, it increased the number of detectable VIP-IR neuronal cell bodies and processes. The stimulatory effects of veratridine were prevented by TTX. Since similar changes in expression of VIP-IR were evident in dissociated cell cultures of the SCG, cell-cell interactions requiring intact ganglionic architecture are not necessary for altered peptide expression. Elevating the concentration of $\mathbf{M g}^{2+}$ blocked the ability of $\mathrm{K}^{+}$and veratridine to increase VIP-IR in dissociated cell culture, raising the possibility that the effects of depolarization on VIP-IR are mediated by increased $\mathrm{Ca}^{2+}$ entry. The depolarizing conditions that increased VIP-IR also increased substance P-IR. While higher concentrations of veratridine $(50 \mu \mathrm{M})$ blocked the elevation of both VIP- and substance P-IR induced by explantation, they produced significant neuronal death. Since depolarization with either $30 \mathrm{~mm} \mathrm{KCl}$ or $1.5 \mu \mathrm{M}$ veratridine increases expression of VIP-IR in neonatal and adult ganglia, decreased depolarization is unlikely to cause the increases in VIP- and substance P-IR that occur in culture. Furthermore, our data raise the possibility that sympathetic nerve activity in vivo can increase expression of these peptides.
\end{abstract}

\footnotetext{
Received Dec. 6, 1991; revised Mar. 5, 1992; accepted Mar. 31, 1992.

This work was supported in part by U.S. PHS Grants NS12651 and HD25681, a postdoctoral fellowship from the Northeast Ohio Affiliate of the American Heart Association (to M.S.R.), and a Research Scientist Award (MH00162 to R.E.Z.).

Correspondence should be addressed to Dr. Richard E. Zigmond at the above address.

Copyright (C) 1992 Society for Neuroscience $0270-6474 / 92 / 123717-12 \$ 05.00 / 0$
}

Most sympathetic neurons in paravertebral ganglia normally contain little, if any, vasoactive intestinal peptide (VIP)-like immunoreactivity (IR). For example, only occasional VIP-IR principal neurons are present in the intact superior cervical ganglion (SCG) of the adult rat (Hokfelt et al., 1977; Sasek and Zigmond, 1989). In the stellate and lower lumbar ganglia, where VIP-IR neurons are somewhat more numerous, they appear to represent some or all of the minority population of cholinergic principal neurons (Lundberg et al., 1979; Lindh et al., 1989). A rapid and striking increase in VIP expression, however, occurs when SCG from adult rats are placed in organ culture. After 24 or $48 \mathrm{hr}$, a significant fraction of SCG neurons contain VIP-IR and the total content of VIP-IR and of the common mRNA for VIP and peptide histidine isoleucine amide (PHI) increases (Zigmond et al., 1992). Since placing ganglia in short-term organ culture would be expected to abolish the firing of postganglionic neurons (Skok, 1973; O'Lague et al., 1975), altered neural activity could be involved in the increase in VIP-IR. Consistent with this possibility, VIP-IR increases when the preganglionic input to the SCG is sectioned in situ (i.e., decentralization). The magnitude of the effect of denervation, however, is much smaller (2-fold) than that obtained in organ culture (30-fold) (HyattSachs et al., 1990).

There is precedent for a role of nerve activity in regulating transmitter biosynthesis in adult sympathetic neurons. For example, in the case of norepinephrine, such a role has been well established. Electrical stimulation of the preganglionic input to the SCG leads to both an acute activation and a delayed induction of tyrosine hydroxylase, the enzyme that catalyzes the rate-limiting step in catecholamine biosynthesis (Zigmond and Bowers, 1981; Zigmond et al., 1989). Antidromic stimulation and depolarization of previously decentralized ganglia by medium containing elevated potassium acutely activates tyrosine hydroxylase (Ip et al., 1983; Rittenhouse et al., 1988). On the other hand, neither of these treatments produces a delayed induction of tyrosine hydroxylase in the adult SCG (Otten and Thoenen, 1976; Chalazonitis and Zigmond, 1980). These data indicate that increased depolarization of postganglionic neurons activates tyrosine hydroxylase but that the effect of preganglionic nerve activity on the induction of tyrosine hydroxylase cannot be explained solely by increased depolarization of postganglionic neurons. In contrast to its effects on catecholamine biosynthesis, depolarization of sympathetic neurons has been reported to inhibit the biosynthesis of a neuropeptide, substance $P$ (Kessler et al., 1981). Placement of the SCG in organ culture causes a large increase in substance $\mathbf{P}$ content that is largely 
blocked by exposure to an elevated concentration of potassium or to veratridine (for a review, see Black et al., 1988).

To determine whether depolarization alters the expression of VIP-IR and whether changes in activity could account for the increase observed following explantation, we have examined the effects of depolarization on SCG neurons in organ and dissociated cell culture. When ganglia were exposed to veratridine or to an elevated concentration of potassium, VIP-IR increased rather than decreased. In addition, we found that substance $P$ levels were similarly regulated. Only when high doses of veratridine that were toxic to the postganglionic neurons were used were levels of VIP- and substance P-IR reduced. Our observations indicate that depolarization increases the expression of VIP-IR and that an environmental factor(s) other than decreased neuronal activity is responsible for the induction of this peptide following explantation or decentralization.

\section{Materials and Methods}

Organ culture. SCG were dissected from Sprague-Dawley rats (Zivic Miller, Allison Park, PA) on postnatal days 0 (referred to here as neonatal ganglia), 7, and 14, and at 4-5 weeks of age (referred to as adult ganglia). The ganglia were put in organ culture on Millipore filters placed on stainless steel rafts. Details of the procedure were as presented in Zigmond and Mackay (1974) and Zigmond et al. (1992), except that 50 $\mathrm{ng} / \mathrm{ml}$ NGF (a gift from Dr. Kenneth Neet) was added to the culture medium. The medium used, $\mathbf{B G J}_{\mathrm{b}}$, contains $6.5 \mathrm{mM} \mathrm{K}$. Ganglia were depolarized by raising the concentration of $\mathrm{K}^{+}$by $30 \mathrm{~mm}$ using $\mathrm{KCl}$ or by adding $1.5 \mu \mathrm{M}$ veratridine (ICN Pharmaceuticals Inc., Plainview, NY). The effect of the addition of $30 \mathrm{~mm} \mathrm{NaCl}$ served as a control for changes due to increased ionic strength. The ability of TTX $(1 \mu \mathrm{M})$ to block the effects of depolarization was also examined. In one experiment, ganglia were taken from rats that had either had their cervical sympathetic trunks cut $2 \mathrm{~d}$ earlier or had undergone a sham operation. These operations were performed under chloral hydrate anesthesia $(770 \mathrm{mg} /$ $\mathrm{kg}$, s.c.). Finally, in certain experiments, the effect of a higher concentration of veratridine $(50 \mu \mathrm{M})$ was studied (Kessler et al., 1981). The SCG were removed from culture after $24 \mathrm{hr}$ and were either frozen at $-80^{\circ} \mathrm{C}$ prior to radioimmunoassay (RIA) or fixed for immunohistochemical or morphological analysis. Control ganglia were fruzen or fixed immediately after removal from the animal.

Cell culture. Dissociated cell cultures of the SCG were prepared as described by Hawrot and Patterson (1979). After dissection from neonatal rats, ganglia were dissociated enzymatically with dispase $(5 \mathrm{mg}$ ) $\mathrm{ml}$; Boehringer Mannheim, Indianapolis, IN) and collagenase (1 mg/ $\mathrm{ml}$; Worthington Biochemical Co., Freehold, $\mathrm{NJ}$ ) at $37^{\circ} \mathrm{C}$ for $1 \mathrm{hr}$, and the cells were plated in 96 well Petri dishes that had been previously coated with polylysine at $100 \mu \mathrm{g} / \mathrm{ml}(100 \mu \mathrm{l} / \mathrm{dish}$; Sigma, St. Louis, MO) and laminin at $5 \mu \mathrm{g} / \mathrm{ml}(100 \mu \mathrm{l} / \mathrm{dish}$; Collaborative Research, Waltham, MA). Cells isolated from 20-26 ganglia were plated into 48 wells, yielding 1000-2000 neurons per well. The neurons were grown in Leibovitz's L-15 $\mathrm{CO}_{2}$ medium with NGF $(100 \mathrm{ng} / \mathrm{ml})$, penicillin $(100 \mathrm{U} / \mathrm{ml})$, streptomycin $(100 \mu \mathrm{g} / \mathrm{ml})$, and rat serum $(5 \%)$. Peptides were extracted from the cells after $24 \mathrm{hr}$ in culture, except for the control cultures, which were extracted after only $4 \mathrm{hr}(t=4)$. In two experiments, the effect of an elevated concentration of $\mathrm{MgCl}_{2}(20 \mathrm{~mm})$ was examined; an elevated concentration of $\mathrm{NaCl}$ was used as a control. All other reagents and their concentrations used were the same as in the organ culture experiments. Although these cultures contained predominantly neurons, they also contained non-neuronal cells.

Radioimmunoassays for VIP- and substance P-IR. Peptides were extracted by boiling ganglia or dissociated cells, which had been scraped from the culture dishes, in $2 N$ acetic acid, $20 \mathrm{~min}$ for the former and $3 \mathrm{~min}$ for the latter. In most experiments, an aliquot of the extract was removed for protein determination by the bicinchoninic acid protcin assay (Pierce, Rockland, IL). The remainder of the supernatant was lyophilized. The lyophilized extracts were reconstituted in assay buffer containing $0.1 \mathrm{~m}$ sodium phosphate (pH 7.3), $0.05 \mathrm{~m} \mathrm{NaCl}, 0.1 \%$ BSA, $0.1 \%$ Triton $\mathrm{X}-100,0.01 \mathrm{M}$ EDTA, $0.01 \% \mathrm{NaN}_{3}$, and $500 \mathrm{KIU} / \mathrm{ml}$ of the protease inhibitor aprotinin (Sigma Chemical Co., St. Louis, MO). Reconstituted extracts of SCG and various concentrations of synthetic VIP (Bachem Inc., Torrance, CA) were incubated for 18-24 hr with a rabbit anti-VIP antiserum (Peninsula Labs, Belmont, CA; final dilution, 1:90,000). ${ }^{125}$ I-VIP (New England Nuclear Research Products, Boston, MA) was added, and the incubation was continued for an additional 24 $\mathrm{hr}$. The antigen-antibody complex was precipitated with goat anti-rabbit $\mathrm{IgG}$ and normal rabbit serum (Peninsula Labs), the resulting precipitate centrifuged, and the pellets counted in a gamma counter. The data were analyzed using Beckman's IMMUNOFIT enzyme immunoassay/RIA analysis software (Beckman Instruments, Fullerton, CA). The sensitivity of the assay (detection limit, approximately $1 \mathrm{pg} /$ tube) allowed the measurement of VIP-IR in an individual SCG. Substance P was assayed in a similar manner using an RIA kit purchased from Incstar (Stillwater, MN). The sensitivity of the substance P RIA was approximately $6 \mathrm{pg}$ / tube.

Immunohistochemistry. The organ cultured ganglia were fixed by immersion in $4 \%$ paraformaldehyde solution in $0.1 \mathrm{M}$ phosphate buffer, pH 7.4, for $1 \mathrm{hr}$. After rinsing with phosphate-buffered saline (PBS), the ganglia were equilibrated with $30 \%$ sucrose in PBS. Cryostat sections $(15 \mu \mathrm{m})$ were thaw mounted onto gelatin-coated slides and processed for indirect immunofluorescence according to the method of Coons (1958). A guinea pig antiserum against VIP (generated by Drs. Paul Henion and Mahendra Rao) was used at dilution of 1:300, and a rabbit antiserum against substance $P$ (Incstar) was used at 1:1000. A mouse monoclonal antibody against tyrosine hydroxylase (a gift from Dr. Ann Acheson) was used at 1:500. Sections were incubated for $1 \mathrm{hr}$ in blocking buffer $(0.5 \mathrm{M} \mathrm{NaCl}, 0.01 \mathrm{~m}$ phosphate buffer, $\mathrm{pH} 7.3,0.1 \% \mathrm{Na}$ azide, and $5 \%$ bovine serum albumin). Primary antisera were diluted in blocking buffer and sections were doubly labeled by simultaneous incubation with two primary antibodies overnight at room temperature. Sections were then rinsed $(3 \times, 15$ min each) in PBS and incubated for $2 \mathrm{hr}$ with the appropriate secondary antisera, rhodamine-conjugated goat antiguinea pig antiserum (1:200; Antibodies Inc., Davis, CA), fluoresceinconjugated goat anti-rabbit antiserum (1:300; Tago, Burlingame, CA), or fluorescein-conjugated goat anti-mouse antiserum (1:300, Tago). These secondary antisera are species specific and do not cross-react with primary antisera raised in other species. The sections were rinsed $(3 \times, 15$ min each) and mounted in a 1:1 mixture of PBS and glycerol. Two controls were run to determine the specificity of the staining: either the primary antiserum was omitted or the primary antisera were incubated with an excess of the appropriate peptide antigen (10 $\mu \mathrm{g}$ of VIP or substance $P$ per $200 \mu 1$ of dilution buffer). Sections were then processed as described above. All staining was abolished by either omitting the primary antiserum or incubating with an excess of the peptide antigen, both indicating that the staining observed on standard conditions was specific.

Ganglionic morphology. The SCG were dissected and fixed immediately or atter $24 \mathrm{hr}$ in organ culture by immersion overnight at room temperature in $2 \%$ paraformaldehyde and $2 \%$ glutaraldehyde in $0.1 \mathrm{~m}$ cacodylate buffer, $\mathrm{pH} 7.4$. Tissue was then rinsed in $0.1 \mathrm{M}$ cacodylate buffer and placed in $2 \%$ osmium tetroxide (Electron Microscopy Sciences, Fort Washington, PA) in cacodylate buffer for $1 \mathrm{hr}$. After washing with acetate buffer, tissue was stained en bloc with $1 \%$ uranyl acetate overnight at $4^{\circ} \mathrm{C}$. The tissue was then dehydrated in ethanol and propylene oxide and embedded in Epon. One micron sections were stained with alcoholic toluidine blue. For all conditions, scetions were examined from at least two ganglia each from three experiments on neonatal ganglia and two experiments on adult ganglia.

Statistics. The data are expressed throughout as mean values \pm SEM. Statistical differences were analyzed by one-way ANOVA, followed by post hoc $t$ tests with Bonferroni correction, except where indicated.

\section{Results}

\section{Effect of depolarization on VIP-IR and substance P-IR in sympathetic ganglia maintained in organ culture}

When nconatal ganglia were placed in organ culture for $24 \mathrm{hr}$, there was a sevenfold increase in VIP-IR $(p<0.05$ by a $t$ test; Fig. 1), similar to the sixfold increase previously reported for adult ganglia (Zigmond et al., 1992). If the explants were exposed to the depolarizing agents $\mathrm{K}^{+}(30 \mathrm{~mm})$ or veratridine $(1.5 \mu \mathrm{M})$ for $24 \mathrm{hr}$, the levels of VIP-IR increased 75- and 63-fold, respectively, when compared to that in noncultured control ganglia $(p<0.001$ for both effects). Increases of the same magnitude were obtained when explants of adult SCG were depolarized 


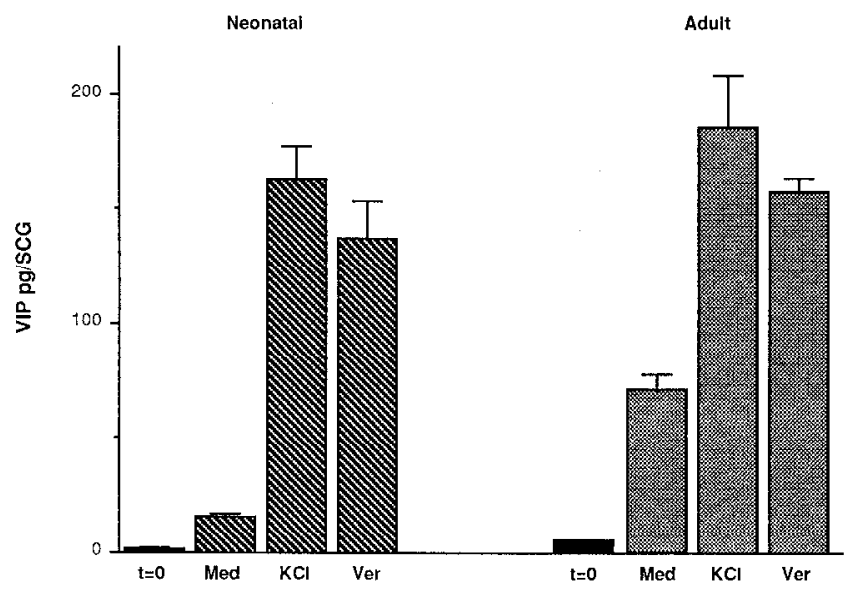

Figure 1. Effect of depolarization on the level of VIP-IR in organ cultures of neonatal and adult SCG. Ganglia were removed from rats and either frozen directly $(t=0)$ or maintained in culture for $24 \mathrm{hr}$ with one of three different types of medium: normal medium (Med; see Materials and Methods), normal medium plus $30 \mathrm{mM} \mathrm{K}^{+}(K C l)$, or normal medium plus $1.5 \mu \mathrm{M}$ veratridine (Ver). Peptides were extracted and VIP-IR was determined by RIA. Each bar represents the mean of at least 10 ganglia. The error measurement used in this figure and throughout the article is the SEM.

(Fig. 1). No significant difference was found between the highpotassium and veratridine groups in either age group. Addition of $30 \mathrm{~mm} \mathrm{NaCl}$ to the medium, instead of $30 \mathrm{~mm} \mathrm{KCl}$, produced no increase in VIP-IR in either neonatal or adult SCG.

The effects of both explantation and depolarization on VIPIR were not affected by age. Results obtained with ganglia taken from animals at four different postnatal ages (i.e., 0, 7, $14 \mathrm{~d}, 4-$ 5 weeks) are compared in Table 1. A stimulation of VIP-IR by elevated $\mathrm{K}^{+}$or veratridine was seen at all ages.

To determine whether depolarization of the cultured SCG affects VIP-IR in postganglionic neurons by an indirect mechanisin involving the release of substances from preganglionic nerve terminals, ganglia were cultured from animals that either had their preganglionic cervical sympathetic trunk sectioned or had undergone a sham operation $2 \mathrm{~d}$ earlier. It has been shown previously that the number of synaptic profiles in the SCG

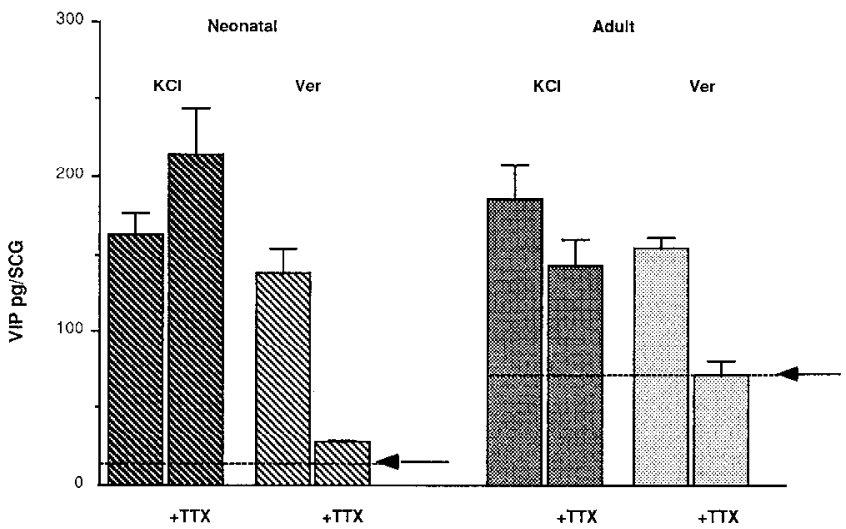

Figure 2. Blockade by TTX $(1 \mu \mathrm{M})$ of the effects of veratridine, but not elevated $\mathrm{KCl}$, on VIP-IR. Both neonatal and adult SCG were cultured for $24 \mathrm{hr}$. Each bar represents the mean of at least four ganglia. The arrows show the level of VIP-IR in neonatal and adult SCG cultured in normal medium for $24 \mathrm{hr}$. The data for the effects of $\mathrm{KCl}$ and veratridine (Ver), in the absence of TTX, are the same as those shown in Figure 1.

decreases by $90 \%$ within the first $24 \mathrm{hr}$ after such a nerve cut (Raisman et al., 1974). The levels of VIP-IR in ganglia cultured in control medium or medium with elevated potassium or veratridine were similar in unoperated ganglia $(77 \pm 11,231 \pm$ 15 , and $120 \pm 0.2$, respectively) and in previously decentralized ganglia (64 $\pm 6,175 \pm 24$, and $130 \pm 13$, respectively). These data indicate that the depolarizing agents increase VIP-IR by acting on cells intrinsic to the SCG, rather than by acting on preganglionic nerve terminals.

The effect of the $\mathrm{Na}^{+}$channel blocker TTX was examined to ascertain whether the effect of veratridine on VIP-IR was mediated via its ability to increase flux through $\mathrm{Na}^{+}$channels. TTX ( $1 \mu \mathrm{M}$ ) completely blocked the stimulation of VIP-IR by veratridine in both neonatal and adult ganglia (Fig. 2). In contrast, TTX had no effect on the ability of elevated $\mathrm{K}^{+}$to increase VIPIR in either group (Fig. 2).

The cellular localization of VIP-IR was examined in control and experimental ganglia from neonatal, 7 and $14 \mathrm{~d}$, and adult rats using immunohistochemistry. Micrographs from ganglia of

Table 1. The effect of explanation and depolarization on the content of VIP-IR and total protein in SCG from rats of different ages: day 0 , day 7 , day 14, and days 28-35

\begin{tabular}{cccccc} 
& Day & Control & Medium & Veratridine & KCI \\
\hline Content of VIP-IR & 0 & $1.7 \pm 0.9$ & $18 \pm 2.5$ & $106 \pm 32$ & $229 \pm 22$ \\
$(\mathrm{pg} / \mathrm{SCG})$ & 7 & $2.8 \pm 0.5$ & $33 \pm 5.3$ & $184 \pm 9.6$ & $265 \pm 36$ \\
& 14 & $4.5 \pm 0.6$ & $94 \pm 22$ & $212 \pm 11$ & $244 \pm 43$ \\
Protein content & $28-35$ & $4.5 \pm 0.5$ & $68 \pm 13$ & $171 \pm 10$ & $187 \pm 22$ \\
$(\mu \mathrm{g} / \mathrm{SCG})$ & 0 & $34 \pm 16$ & $24 \pm 2.1$ & $34 \pm 19$ & $28 \pm 4.6$ \\
& 7 & $47+2.0$ & $71+4.5$ & $73+2.4$ & $70+4.2$ \\
& 14 & $90 \pm 11$ & $132 \pm 17$ & $110 \pm 7.8$ & $83 \pm 19$ \\
VIP-IR/mg of protein & $28-35$ & $144 \pm 27$ & $165 \pm 11$ & $161 \pm 2.3$ & $154 \pm 10$ \\
$(\mathrm{pg} / \mathrm{mg})$ & 0 & $94 \pm 60$ & $761 \pm 116$ & $5634 \pm 2213$ & $8684 \pm 1612$ \\
& 7 & $62 \pm 11$ & $478 \pm 80$ & $2538 \pm 150$ & $3828 \pm 545$ \\
& 14 & $53 \pm 10$ & $723 \pm 146$ & $1946 \pm 93$ & $3251 \pm 449$ \\
& $28-35$ & $34 \pm 6.1$ & $166 \pm 147$ & $1067 \pm 77$ & $1224 \pm 141$
\end{tabular}

Control condition indicates uncultured SCG, which were frozen directly after dissection. Medium indicates ganglia cultured in normal medium for $24 \mathrm{hr}$. Veratridine and $\mathrm{KCl}$ indicate ganglia cultured in medium containing $30 \mathrm{~mm} \mathrm{KCl}$ or $1.5 \mu \mathrm{M}$ veratridine. Four ganglia were included in each group. 

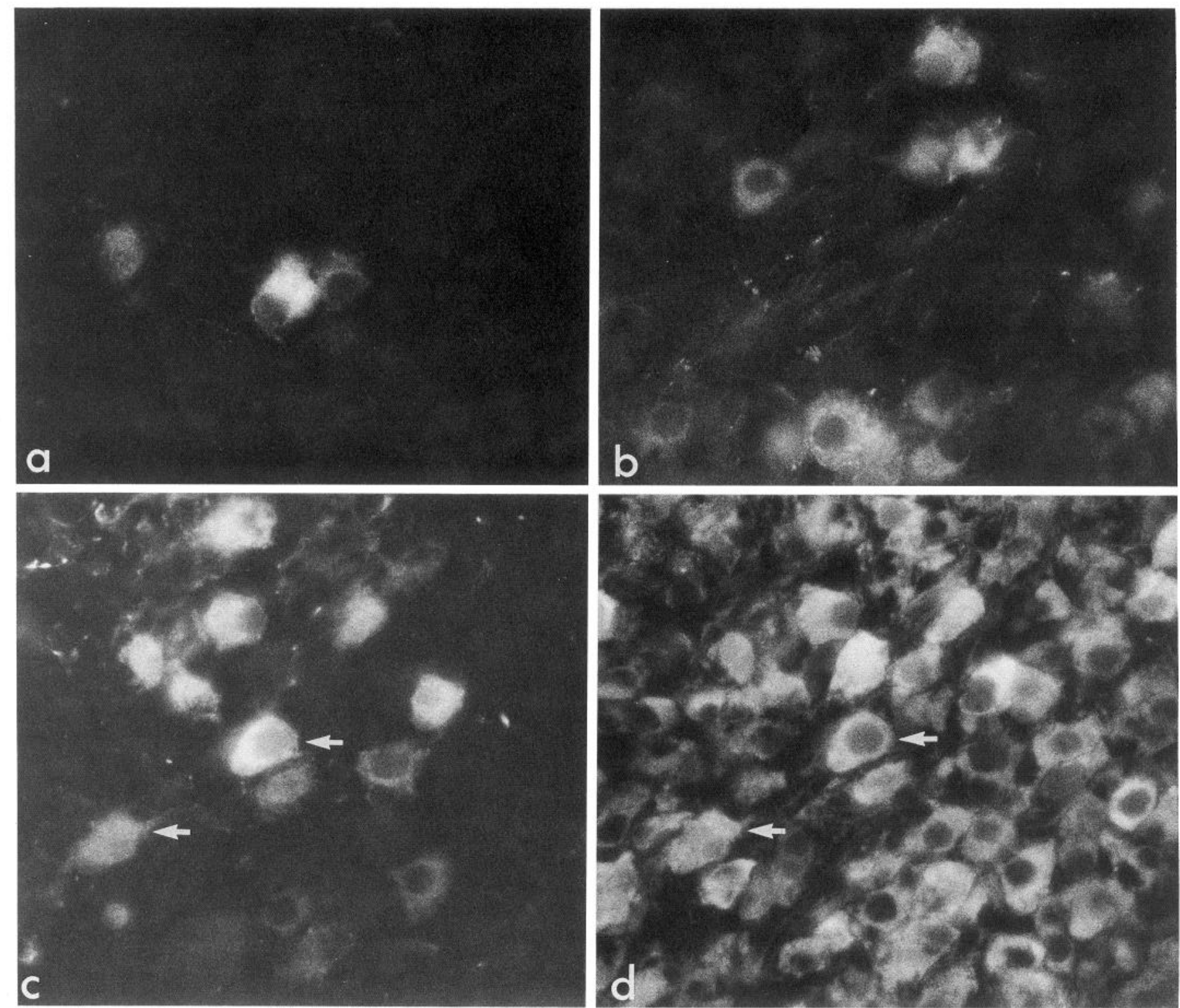

Figure 3. Immunohistochemical examination of the effects of depolarization on VIP-IR in SCG. Cryostat sections of ganglia from 14-d-old rat pups were doubly labeled for VIP and tyrosine hydroxylase immunoreactivity after $24 \mathrm{hr}$ in culture. $a$, Ganglia grown in control medium contained scattered VIP-IR neurons. $b$, Ganglia grown in the presence of $30 \mathrm{~mm} \mathrm{~K}{ }^{+}$contained many more immunoreactive neurons and processes. Ganglia grown in the presence of $1.5 \mu \mathrm{M}$ veratridine contained numerous VIP-IR neurons and processes. $c$, Tyrosine hydroxylase staining of the same field is shown in $d$. All the VIP-IR neurons contained immunoreactivity for tyrosine hydroxylase as well. The arrows in $c$ and $d$ indicate one doubly labeled neuron. Magnification, $420 \times$.

14-d-old rats are shown in Figure 3, but similar distributions were observed at the other ages examined. More VIP-IR neuronal cell bodies were evident in SCG cultured in control medium than in normal ganglia, as previously described for cultures of adult ganglia (Zigmond et al., 1992). Depolarization with either veratridine $(1.5 \mu \mathrm{M})$ or potassium $(30 \mathrm{mM})$ further increased the number of immunoreactive neurons, consistent with the results from RIA. In addition, it caused a striking increase in the number of immunoreactive fibers present in the ganglia. Sections were examined for both VIP and tyrosine hydroxylase immunoreactivity to determine whether the VIP-IR was present in noradrenergic principal neurons. In ganglia in situ, the rare VIP-IR neurons that are present do not possess immunohistochemically detectable levels of tyrosine hydroxylase (P. Henion, S. Tyrrell, and S. C. Landis, unpublished observations). In contrast, following explantation or explantation and depolarization, virtually all VIP-IR neuronal cell bodies also contained immunoreactivity for tyrosine hydroxylase (Fig. $3 c, d$ ).

Our results raised the possibility that the regulation of VIPIR differs from that of substance P-IR in explanted SCG (Kessler et al., 1981; Adler and Black, 1984). In those studies, while substance $\mathbf{P}$ content significantly increased after explantation, depolarization with veratridine $(50-200 \mu \mathrm{M})$ completely blocked this increase. To mimic more closely the culture conditions used in these previous studies, a higher concentration of veratridine $(50 \mu \mathrm{M})$ was used. At this concentration, veratridine blocked the increase in VIP-IR in cultured adult ganglia $(p<0.01)$, although in the same experiment $1.5 \mu \mathrm{M}$ veratridine significantly increased peptide levels $(p<0.001 ;$ Fig. 4$)$. The inhibitory effect of $50 \mu \mathrm{M}$ veratridine, like the stimulatory effect of $1.5 \mu \mathrm{M}$ ve- 
ratridine, was totally reversed by TTX ( $p<0.01$ for comparison of $50 \mu \mathrm{M}$ veratridine vs. veratridine plus TTX). In neonatal ganglia, $50 \mu \mathrm{M}$ veratridine appeared to produce a stimulation of VIP-IR. (This increase was statistically significant, $p<0.05$, when post hoc $t$ tests were done only on a subset of the data, i.e., ganglia cultured in normal medium, $50 \mu \mathrm{M}$ veratridine [Ver(H)] and $50 \mu \mathrm{M}$ veratridine plus TTX.) In the same experiment, $1.5 \mu \mathrm{M}$ veratridine significantly increased VIP-IR in neonatal ganglia $(p<0.001)$. When sections of neonatal ganglia treated with $50 \mu \mathrm{M}$ veratridinc werc staincd for VIP and tyrosinc hydroxylase immunoreactivity and examined, the tissue looked poorly preserved and few neurons exhibited the expected levels of tyrosine hydroxylase immunoreactivity (data not shown). These observations raised the possibility that under certain conditions, such as high concentrations of veratridine, the organ culture system might not support neuronal survival.

To assess directly the effects of organ culture and the depolarizing agents on neuronal survival and morphology, neonatal and adult SCG were fixed immediately after dissection or after $24 \mathrm{hr}$ in culture and semithin sections from the plastic embedded ganglia were examined. The majority of the neurons in neonatal ganglia that had not been cultured or had been cultured for 24 hr either in the presence or absence of low concentrations of veratridine (1.5 $\mu \mathrm{M}$ ) exhibited a normal morphology (Fig. 5). Their nuclei and nucleoli were distinct and the cytoplasm appeared uniformly textured. It is of interest that neurons in ganglia cultured with $1.5 \mu \mathrm{M}$ veratridine appeared healthier than those in control medium; this is consistent with previous reports that depolarization can enhance the survival of developing sympathetic neurons (Wakade and Thoenen, 1984; Koike et al., 1989). In contrast, neonatal ganglia cultured with $50 \mu \mathrm{M}$ veratridine contained relatively few neurons that appeared morphologically normal while vacuoles and dark, degenerating profiles were common (Fig. 5). Like the neonatal ganglia, adult ganglia fixed immediately after dissection or culturing for $24 \mathrm{hr}$ in normal medium, or in medium containing $1.5 \mu \mathrm{M}$ veratridine or elevated potassium, contained almost exclusively profiles of morphologically normal neurons (Fig. 6). Similarly, culture of adult ganglia in $50 \mu \mathrm{M}$ veratridine caused both dark degeneration and the appearance of large vacuoles. In many sections, the adult ganglia appeared to be more adversely affected by the high concentrations of veratridine than were the neonatal ganglia. Inclusion of TTX prevented the apparently toxic effects of 50 $\mu \mathrm{M}$ veratridine on both neonatal and adult ganglia (data not shown).

The regulation of VIP-IR in organ cultures of neonatal SCG was directly compared with that of substance P-IR. Kessler et al. (1983) have shown that the substance P-IR in cultured SCG coelutes with authentic substance $P$ on HPLC. Under our experimental conditions, levels of substance P-IR changed in parallel with those of VIP-IR. Substance P-IR increased in organ culture after $24 \mathrm{hr}(p<0.05$; Fig. 7), as previously reported (Kessler et al., 1981). Depolarization with either $30 \mathrm{~mm} \mathrm{~K}^{+}$or $1.5 \mu \mathrm{M}$ veratridine, however, further increased substance P-IR ( $p<0.01$ for both; Fig. 7). The increase produced by $1.5 \mu \mathrm{M}$ veratridine was blocked by TTX. When ganglia cultured in normal medium for $24 \mathrm{hr}$ were examined by immunocytochemistry for the presence of substance $\mathbf{P}$, only occasional neuron cell bodies were detectably immunoreactive (Fig. 8). If ganglia were depolarized either with elevated potassium (Fig. 8) or $1.5 \mu \mathrm{M}$ veratridine (Fig. 9), the number of immunoreactive cell bodies was significantly increased. In general, the neurons were less

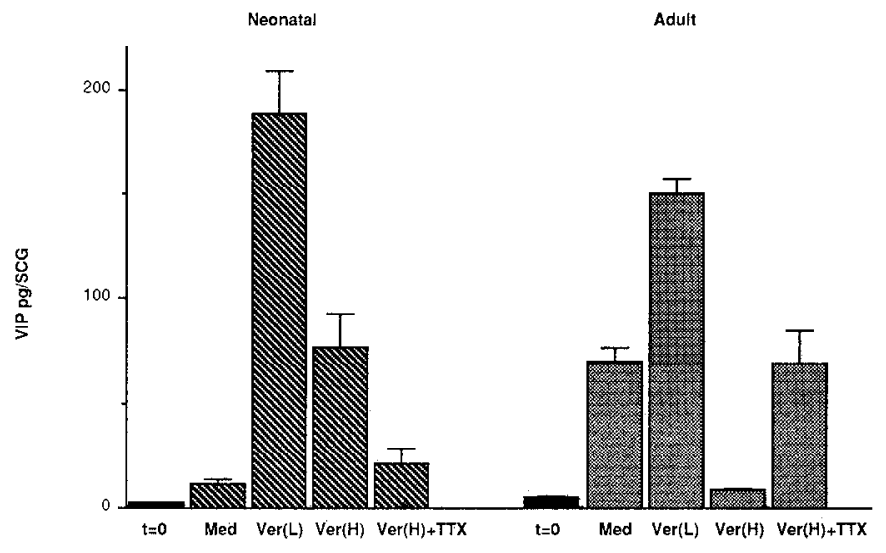

Figure 4. The effect of a higher concentration of veratridine $(50 \mu \mathrm{M})$ on VIP-IR in the SCG and its reversal by TTX. Both neonatal and adult SCG were cultured for $24 \mathrm{hr}$ in the presence of normal medium $(M e d)$, normal medium plus $1.5 \mu \mathrm{M}$ veratridine [ $\operatorname{Ver}(L)]$, medium plus $50 \mu \mathrm{M}$ veratridine $[\operatorname{Ver}(H)]$, or medium plus $50 \mu \mathrm{M}$ veratridine and $1 \mu \mathrm{M}$ TTX $[\operatorname{Ver}(H) \pm T T X]$. The data represent the means \pm SEM for at least four ganglia.

intensely immunoreactive for substance $P$ and the immunoreactivity was more variable in its intensity than in the case of VIP. It is possible that additional neurons contain substance P-IR but are below the level of detcction using immunofluorescence. In explant culture, although many neurons exhibit VIP- or substance P-IR, they still represent a minority of the cells in the ganglion. To determine whether the induction of these peptides occurs in the same or different populations of neurons, colocalization studies were carried out. Both doubly labeled and singly labeled neurons were seen (Fig. 9).

\section{Effect of depolarization of sympathetic neurons in dissociated cell culture on VIP-IR}

To determine whether the effects of explantation and depolarization on expression of VIP-IR described above require cellcell interactions that depend upon the normal ganglionic cytoarchitecture, short-term dissociated cell cultures were established. Dissociated cell cultures also provide the opportunity to control more precisely the concentration of drugs to which sympathetic neurons are exposcd than does the organ culture system. When neonatal ganglia were dissociated and placed in culture for $24 \mathrm{hr}$, there was a large (28-fold) increase in VIP-IR in comparison to that found in neurons $4 \mathrm{hr}$ after plating ( $p<$ 0.001 ; Fig. 10). Addition of either $\mathrm{K}^{+}(30 \mathrm{~mm})$ or veratridine $(1.5 \mu \mathrm{M})$ produced a further increase in peptide levels $(p<0.05$ for both). As in explant cultures, the effects of veratridine, but not those of $\mathrm{K}^{\dagger}$, were blocked by TTX. The ionic basis of the effect of depolarization was examined further by depolarizing neurons in medium containing an elevated concentration of $\mathrm{MgCl}_{2}(20 \mathrm{~mm})$ to block $\mathrm{Ca}^{2+}$ channels. Addition of $\mathrm{Mg}^{2+}$ blocked the increases in VIP-IR produced by both $\mathrm{K}^{+}$(Fig. 11) and veratridine (Fig. 12).

\section{Discussion}

In the present study, we have shown that expression of immunorcactivity for the neuropeptide VIP is rapidly increased in the SCG following depolarization of the neurons in either organ or dissociated cell culture. This increase is evident not only in ganglia from neonatal rats but also in ganglia from adult rats. Our data suggest that $1.5 \mu \mathrm{M}$ veratridine leads to an influx 

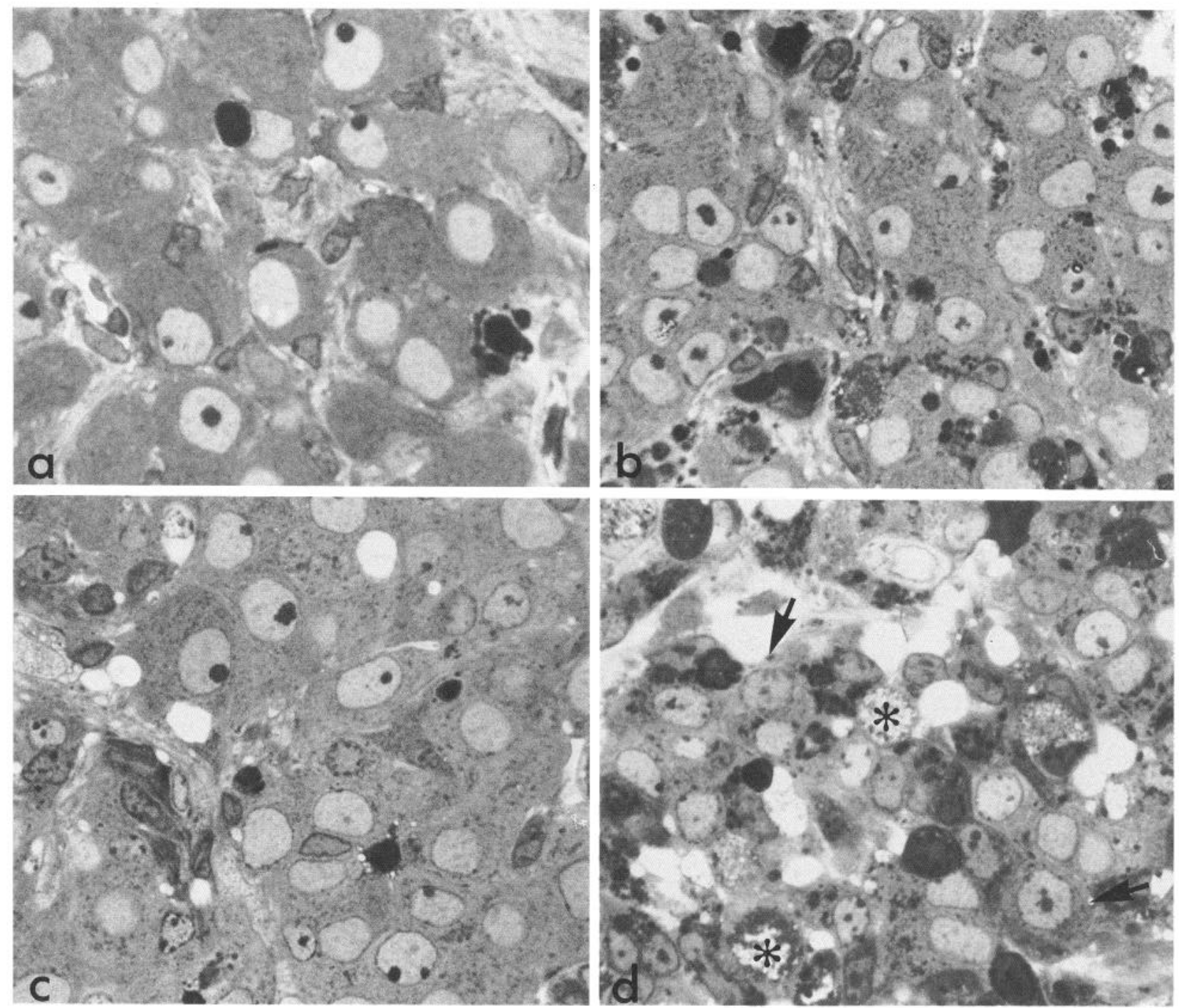

Figure 5. Histological appearance of neonatal SCG cultured in normal medium or medium containing $1.5 \mu \mathrm{M}$ or $50 \mu \mathrm{M}$ veratridine. Ganglia were removed from newborn rat pups and either fixed immediately or cultured for $24 \mathrm{hr}$ before fixation. Semithin plastic sections were stained with toluidine blue. $a$, Neurons in ganglia fixed without culture appear healthy with large clear nuclei, prominent nucleoli, and even granular cytoplasm. $b$, Many neurons appear healthy after culture in control medium. Some debris is evident, resulting in part from changes in blood vessel components. $c$, Following culture in $1.5 \mu \mathrm{M}$ veratridine, the majority of the neurons appear indistinguishable from those in uncultured ganglia. Occasional vacuoles are present. $d$, Culture in the presence of $50 \mu \mathrm{M}$ veratridine causes the degeneration of most neurons. Many cells exhibit dark degeneration or the presence of numerous small vacuoles (asterisks). The arrow indicates neurons exhibiting a more normal morphology. Magnification, $700 \times$.

of $\mathrm{Na}^{+}$via voltage-sensitive channels, followed by increased $\mathrm{Ca}^{2+}$ entry and a subsequent increase in VIP-IR. Depolarization by elevated $\mathrm{K}^{+}$also appears to increase VIP-IR via an increase in $\mathrm{Ca}^{2+}$ entry that does not depend on the opening of $\mathrm{Na}^{+}$channels. The magnitudes of the changes in peptide expression reported here are probably underestimations, since we assayed peptide content of the neurons and both veratridine and elevated $\mathrm{K}^{+}$would be expected to cause the release of neuropeptides from sympathetic neurons into the medium (e.g., Kessler et al., 1983).

The induction of VIP-IR by depolarization is rapid and does not appear to depend upon the developmental stage of the neurons. Significant elevations are detected within $24 \mathrm{hr}$ in both organ and dissociated cell cultures. Examination of long-term cultures of neurons dissociated from neonatal ganglia indicates that the increased expression of VIP-IR in response to depolarization reported here is not transient but is maintained (Rao et al., 1992). The ability of noradrenergic sympathetic neurons to respond to depolarization with an elevation in VIP-IR does not change detectably with maturation. Striking increases were observed in organ cultured ganglia from rats that ranged in age from newborn to 6 weeks. The continued responsiveness of the levels of VIP-IR to depolarization contrasts with the loss of responsiveness of tyrosine hydroxylase to depolarization described by Hefti et al. (1982). Similarly, the ability of cultured sympathetic neurons to acquire cholinergic function decreases with increasing neuronal age (Patterson and Chun, 1977; Johnson et al., 1980; Potter et al., 1986). This raises the possibility that in sympathetic neurons plasticity of neuropeptide expression may be regulated differently than that of classical or small molecule transmitters. The effects of depolarization on expression of VIP-IR are not restricted to sympathetic neurons since the level of VIP mRNA in dissociated cell cultures of mice spinal cord/dorsal root ganglion is decreased when electrical activity in the culture is inhibited with TTX (Agoston et al., 1991). 

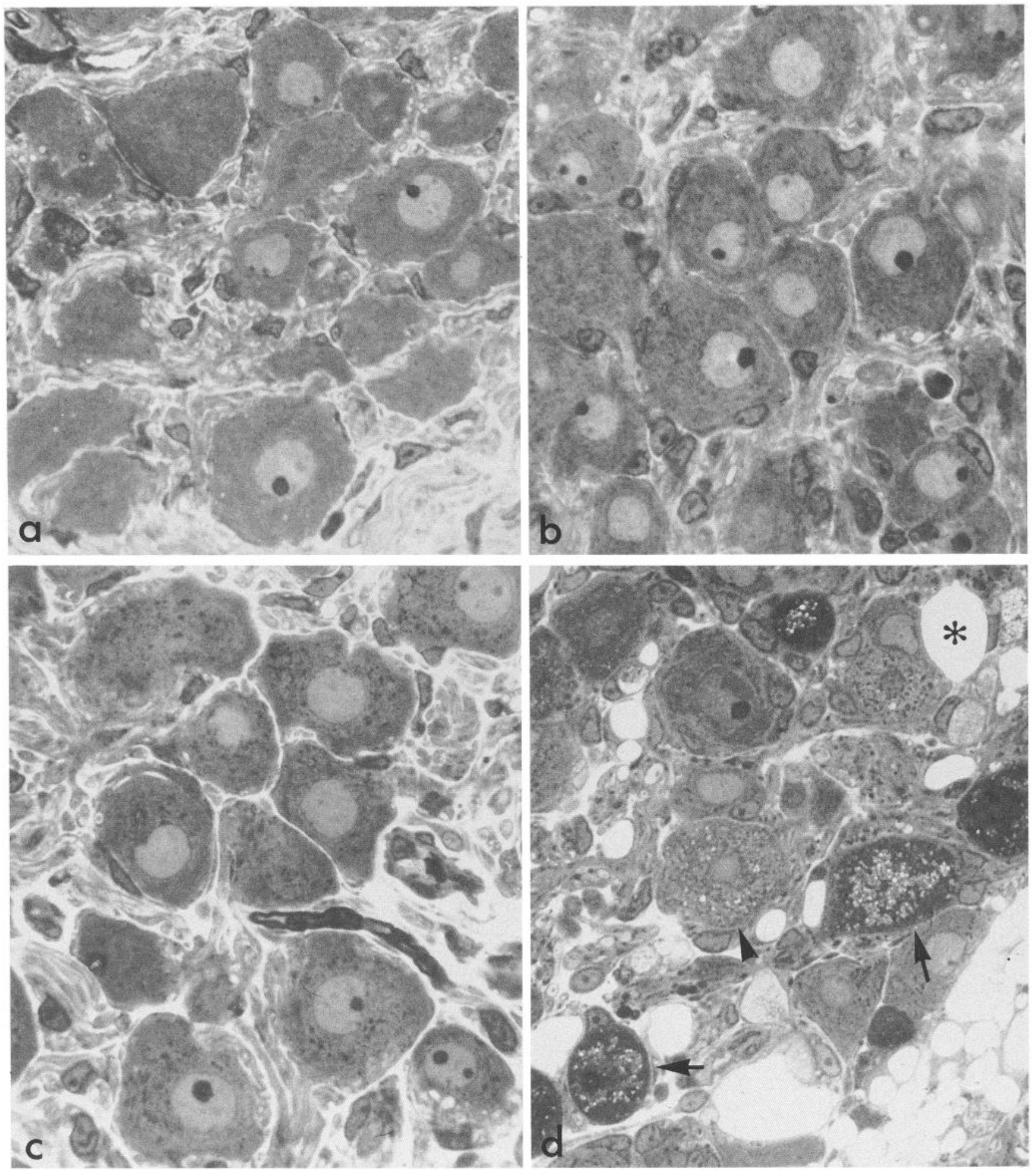

Figure 6. Histological appearance of adult SCG cultured in normal medium or medium containing $1.5 \mu \mathrm{M}$ or $50 \mu \mathrm{M}$ veratridine. Ganglia were removed from newborn rat pups and either fixed immediately or cultured for $24 \mathrm{hr}$ before fixation. Semithin plastic sections were stained with toluidine blue. $a$, Neurons in ganglia fixed without culture appear healthy with large clear nuclei, prominent nucleoli, and evenly granular cytoplasm. $b$, Many neurons appear healthy after culture in control medium, although nuclei of some neurons are eccentric, consistent with a chromatolytic response. No degenerating profiles are evident. $c$, Following culture in $1.5 \mu \mathrm{M}$ veratridine, the neurons appear similar to those in uncultured ganglia. $d$, Culture in the presence of $50 \mu \mathrm{M}$ veratridine causes a variety of morphological changes in neuronal soma. Many cells exhibit dark degeneration (arrows) or the presence of numerous small vacuoles (arrowhead). Large, clear vacuoles are present both in axon bundles and associated with nerve cell bodies. Only occasional neurons appear unaffected. Magnification, $700 \times$. 


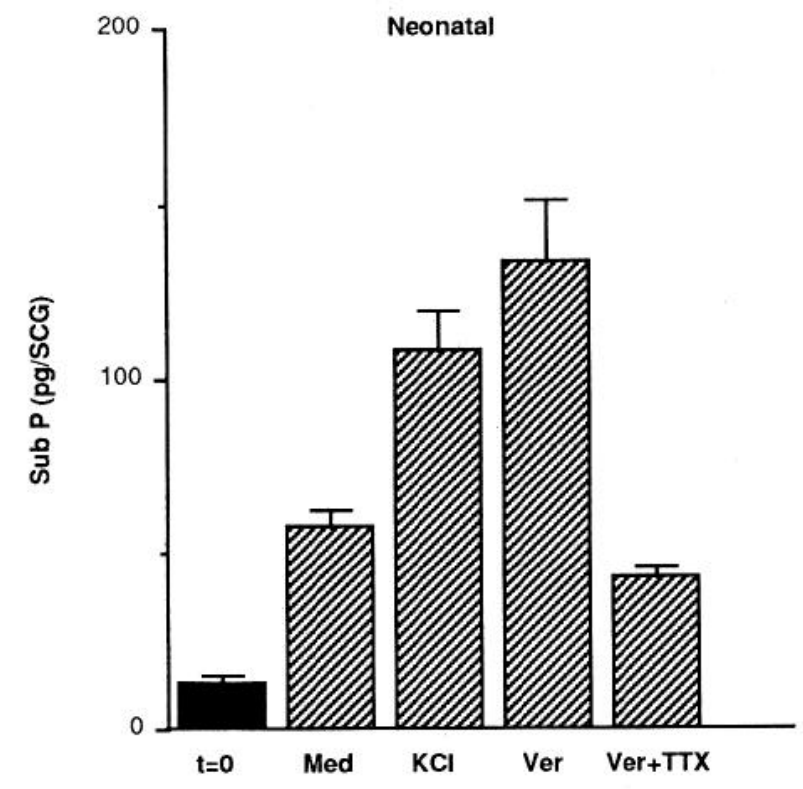

Figure 7. Effect of depolarization on the level of substance P-IR in neonatal SCG in organ culture. Ganglia were removed from rats and either frozen directly $(t=0)$ or maintained in organ culture using one of four different media: normal medium $(M e d), 30 \mathrm{mM} \mathrm{KCl}(K C l), 1.5 \mu \mathrm{M}$ veratridine $(\mathrm{Ver})$, or veratridine plus TTX $(\mathrm{Ver}+T T X)$. Each bar represents the mean of at least 10 ganglia.

The effect of depolarization on VIP-IR appeared to be reversed if the concentration of veratridine was increased. While $1.5 \mu \mathrm{M}$ veratridine elevated the content of VIP-IR in explants of adult ganglia, a 33-fold higher concentration of veratridine, $50 \mu \mathrm{M}$, totally inhibited the increase. When semithin sections of adult ganglia cultured in the higher concentration of verat- ridine were examined, many neurons displayed morphological changes indicative of necrosis. Vacuoles and dark, degenerating profiles were common. This is in marked contrast to the healthy appearance of the neurons cultured in normal medium, $1.5 \mu \mathrm{M}$ veratridine, and elevated potassium. The morphological effects of $50 \mu \mathrm{M}$ veratridine were seen in both adult and neonatal ganglia, but the effects appeared greater in the former. This difference could account for the fact that in neonatal ganglia $50 \mu \mathrm{M}$ veratridine produced a small stimulation of VIP-IR, though much less of a stimulation than did $1.5 \mu \mathrm{M}$ veratridine. The effects of the higher concentration of veratridine on the content of VIP-IR and neuronal survival, like the effects of the lower concentration on the content of VIP-IR, were blocked by TTX. It seems likely that chronic exposure to $50 \mu \mathrm{M}$ veratridine leads to "excessive" $\mathrm{Ca}^{2+}$ entry and activation of $\mathrm{Ca}^{2+}$-dependent proteases. Such a hypothesis has been proposed to account for the toxic effects of chronic exposure to $\mathrm{AChE}$ inhibitors at the neuromuscular junction (Salpeter et al., 1979) and of excitatory amino acids at CNS synapses (for review, see Choi and Rothman, 1990). It is noteworthy that when Walicke et al. (1977) and Betz and Changeux (1979) examined the effects of depolarization with veratridine on the regulation of catecholamine biosynthesis and nicotinic receptors, respectively, they used the depolarizing agent at a concentration of $1.5 \mu \mathrm{M}$.

Immunohistochemical studies indicate that the VIP-IR in cultured SCG, even after depolarization, is evident in only a proportion of neurons (Zigmond et al., 1992; present results). Normally, in adult sympathetic ganglia, VIP-IR is present in a subpopulation of principal neurons, which is thought to be cholinergic (Lundberg et al., 1979; Lindh et al., 1989), but not in noradrenergic neurons. Following explantation, even in the absence of depolarization, VIP-IR in the SCG was colocalized with tyrosine hydroxylase-IR. These observations suggest that under our experimental conditions, the vast majority of neurons
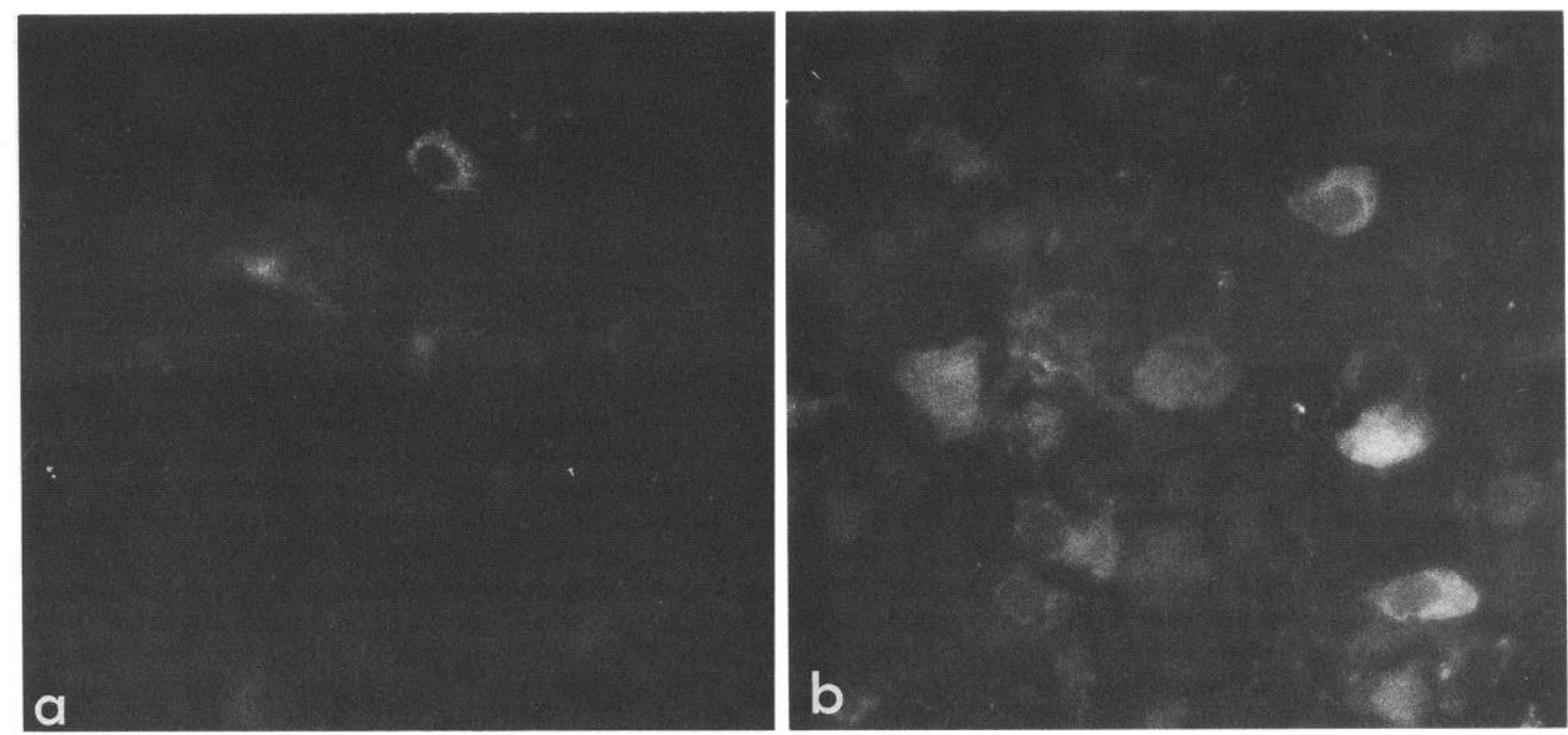

Figure 8. Immunohistochemical examination of changes in substance P-IR. Cryostat sections of ganglia from 14-d-old rat pups were labeled for substance P-IR after $24 \mathrm{hr}$ in culture. $a$, In normal medium, a small proportion of neurons contain detectable immunoreactivity for substance P. $b$, Following culture in $30 \mathrm{~mm} \mathrm{~K} \mathrm{~K}^{+}$, many neurons contain substance $\mathrm{P}$. Magnification, $420 \times$. 

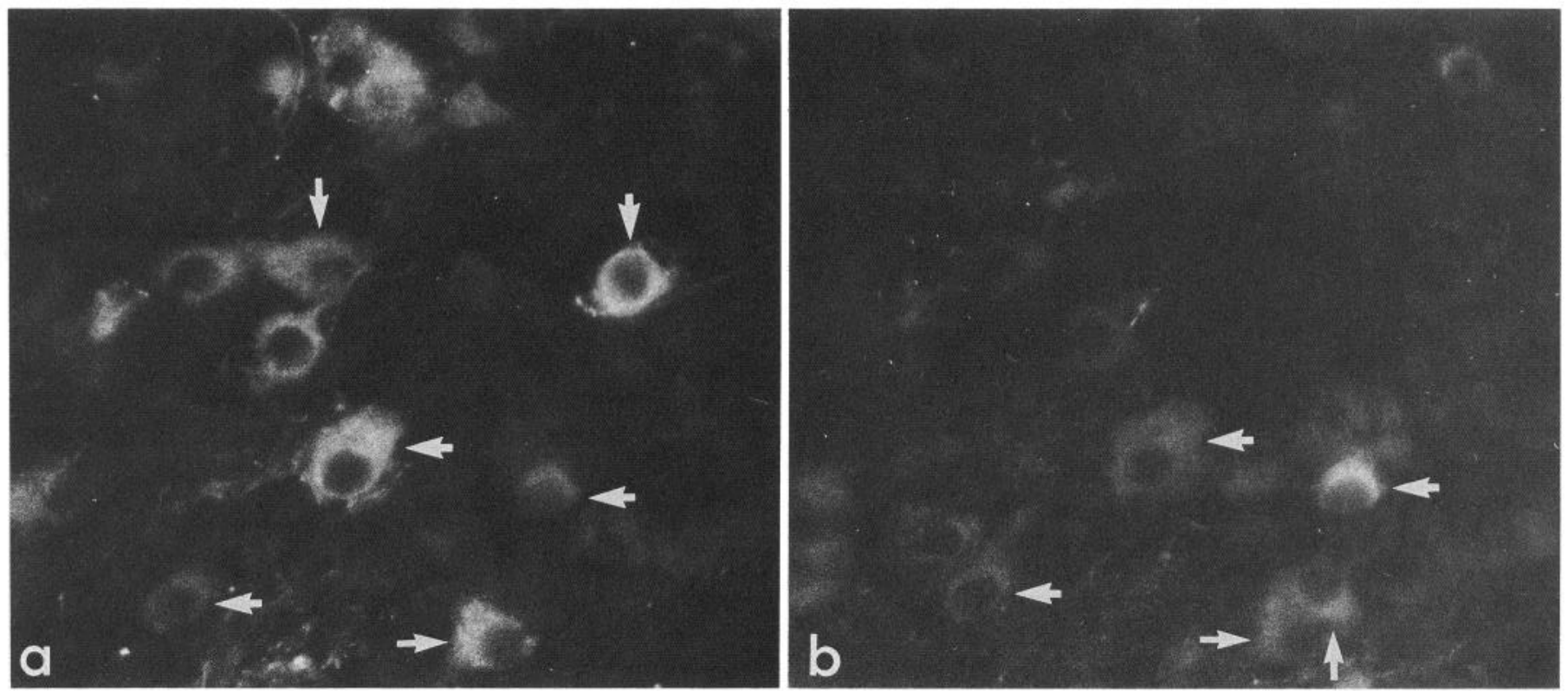

Figure 9. Double labeling with antisera against VIP and substance P. Cryostat sections of ganglia from 14-d-old rat pups were doubly labeled for VIP- (a) and substance P- (b) IR after $24 \mathrm{hr}$ in $1.5 \mu \mathrm{M}$ veratridine. The horizontal arrows indicate neurons that contain immunoreactivity for both neuropeptides while the vertical arrows indicate examples of neurons that contain immunoreactivity for one but not both. Magnification, $420 \times$.

that express VIP-IR are noradrenergic principal neurons. This is in contrast to the expression of VIP-IR in sympathetic neurons cultured from avian ganglia (Hayashi et al., 1985; Garcia-Arraras, 1991). As in the case of rat ganglia, dissociation of embryonic quail ganglia and growth in culture leads to an increase in VIP-IR and depolarization for 4-7 d with $1.5 \mu \mathrm{M}$ veratridine or $20 \mathrm{~mm} \mathrm{~K}^{+}$increases this IR two- and fivefold further, respectively. At least in normal medium, however, the quail sympathetic neurons that express VIP-IR do not contain detectable catecholamines and are not noradrenergic; colocalization studies, however, were not performed after depolarization (GarciaArraras, 1991).

The effects of depolarization on the expression of substance $\mathrm{P}$ in neonatal ganglia in organ culture were similar to those on

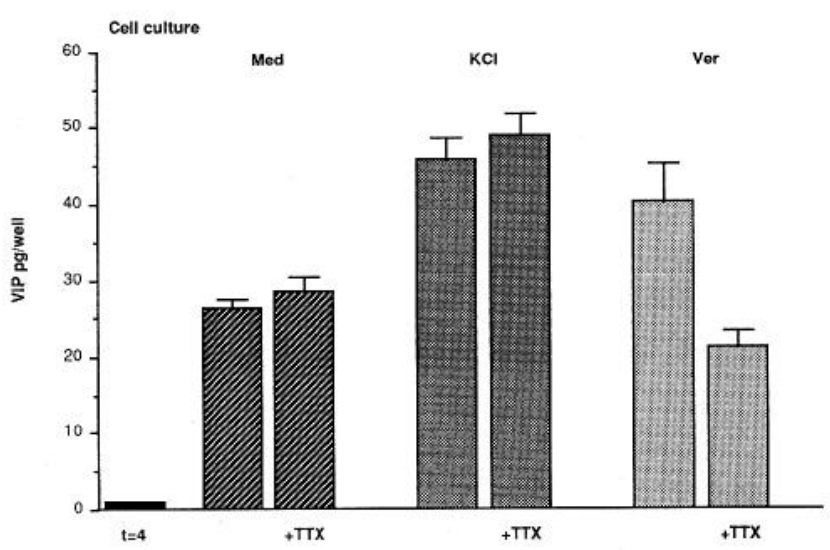

Figure 10. Effects of depolarization on the level of VIP-IR in dissociated cell culture, and the influence of TTX on these effects. Ganglia were dissociated and neurons and non-neuronal cells were plated for either $4(t=4)$ or $24 \mathrm{hr}$. The cells were cultured in normal medium $(\mathrm{Med}), 30 \mathrm{~mm} \mathrm{KCl}(\mathrm{KCl})$, or $1.5 \mu \mathrm{M}$ veratridine $(\mathrm{Ver})$. Each bar represents the mean values for at least seven culture wells. the expression of VIP-IR. As previously reported, we found that placing the SCG in organ culture leads to about a $10-40$-fold increase in substance P (Kessler et al., 1981; Adler and Black, 1984). Low concentrations of veratridine $(1.5 \mu \mathrm{M})$, which cause little or no neuronal damage, result in a clear stimulation of the expression of substance P. However, like Kessler and Black, we

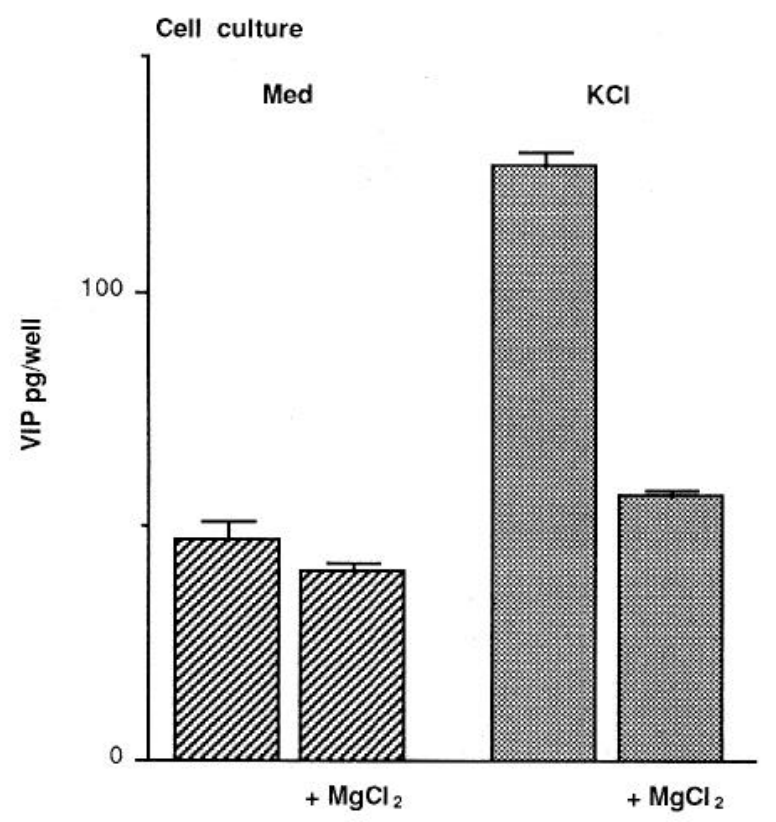

Figure 11. Effect of $\mathrm{Mg}^{2+}$ on the stimulation of VIP-IR in dissociated cell culture by $\mathrm{K}^{+}$. In this experiment, due to the need to change the concentrations of both $\mathrm{Mg}^{2+}$ and $\mathrm{K}^{+}$, the total ionic strength of the medium was kept constant by lowering the $\mathrm{Na}^{+}$concentration. Cells were incubated in normal medium $(\mathrm{Med})$ or in medium containing 30 m $\mathrm{MCl}(\mathrm{KCl})$. In some cultures, $\mathrm{MgCl}_{2}(20 \mathrm{~mm})$ was also included in the medium. The data represent the means for eight culture wells. 


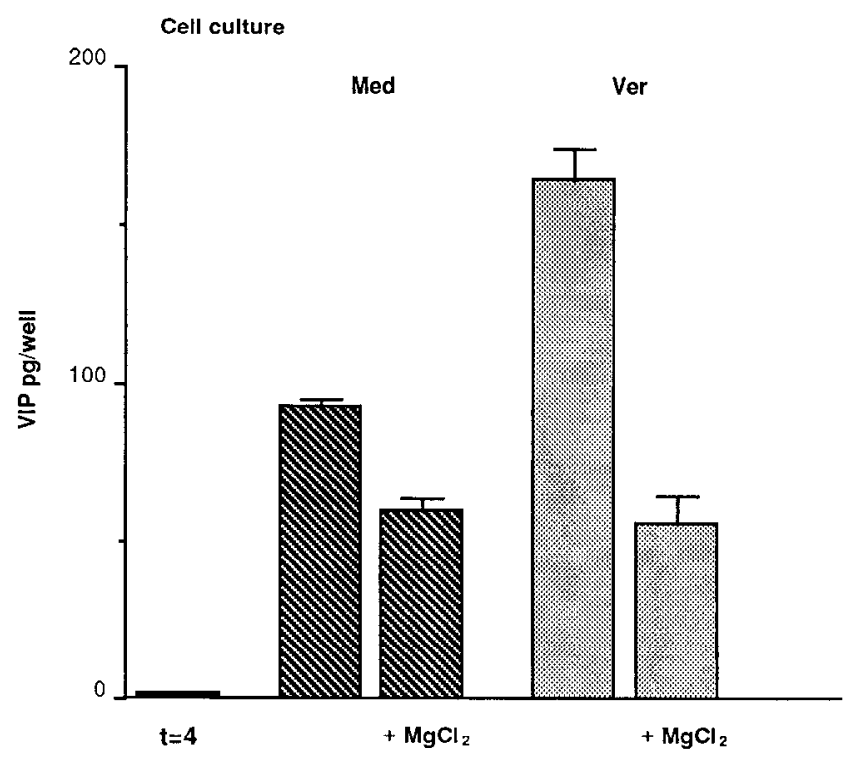

Figure 12. Effect of $\mathrm{Mg}^{2+}$ on the stimulation of VIP-IR in dissociated cell culture by veratridine. Cells were incubated in normal medium $(\mathrm{Med})$ or in medium plus $1.5 \mu \mathrm{M}$ veratridine (Ver). In some cultures, $\mathrm{MgCl}_{2}$ (20 mM) was also included in the medium. The data represent the means for three culture wells.

found that higher concentrations of veratridine (50-200 $\mu \mathrm{M})$ abolish the increase in peptide content normally seen in culture (Kessler et al., 1981, 1983; Adler and Black, 1984). Because veratridine suppresses the elevation of substance $P$ and because an increase in substance $P$, although much smaller in magnitude, is observed after decentralization (Kessler and Black, 1982), Kessler and Black suggested that the increased substance P-IR found after explanation is due to a decrease in neuronal activity and that the expression of this peptide in the SCG in vivo is normally suppressed by ongoing sympathetic neural activity (Kessler et al., 1981; Adler and Black, 1984; Black et al., 1988). A similar case has been made for the regulation of enkephalin in adrenal chromaffin cells by activity (Schultzberg et al., 1978; Lewis et al., 1981; LaGamma et al., 1984). Our data, however, indicate that the decrease in substance P-IR seen in organ cultures of SCG treated with high concentrations of veratridine, like the decrease in VIP-IR seen with $50 \mu \mathrm{M}$, represents a toxic effect of the depolarizing agent. Although the results obtained with veratridine are consistent, differences exist in the effects reported after depolarization with elevated $\mathrm{K}^{+}$; substance $\mathrm{P}$ induction is suppressed by $60 \%$ by $55 \mathrm{~mm}$ potassium (Kessler and Black, 1983) while we found that $30 \mathrm{~mm}$ potassium caused an increase in substance P- as well as VIP-IR. It is possible that the extent of $\mathrm{Ca}^{2+}$ influx under these two conditions could be a factor here as in the case of veratridine-containing media.

After $24 \mathrm{hr}$, substance P-IR, like VIP-IR, was detected in a minority of neurons in ganglia cultured in a depolarizing medium. Neurons often contained both VIP- and substance P-IR, and it is our impression that the number of these doubly labeled neurons is grcater than onc would expect based on chance alone, given the frequency of neurons containing immunoreactivity for each peptide. The relatively restricted expression of the two peptides raises the question of whether certain characteristics of particular postganglionic neurons predispose them to express one, both, or neither of these peptides, when placed in culture under depolarizing conditions.

\section{Comparison of the effects of decentralization and explantation on peptide levels}

The examination of the effects of depolarization on the expression of VIP-IR was initiated to test the hypothesis that the primary factor regulating the expression of VIP-IR in organ culture is a decrease in sympathetic nerve activity, as had been suggested for substance P. Based on the findings of the present study, this explanation seems unlikely. Furthermore, there are a number of differences in the effects produced by decentralization and explantation. Although most evidence indicates that both procedures increase the levels of the two peptides, the increases seen in organ culture are much larger than those found after decentralization (but see Gurusinghe and Bell, 1989, and Robinson et al., 1980, who report a decrease and no effect, respectively, on substance $\mathbf{P}$ levels following decentralization of the rat $\mathrm{SCG}$ ). Decentralization leads to an approximatcly 2 -fold increase in VIP- and substance P-IR (Kessler et al., 1981; Kessler and Black, 1982; Hyatt-Sachs et al., 1990), while placing the ganglion in organ culture leads to about a 10-40-fold increase in these peptides (Kessler et al., 1981; Adler and Black, 1984; Zigmond et al., 1992). Further, at least in the case of VIP, the distribution of peptide-IR differs under the two conditions. Following decentralization, an increase in VIP-IR nerve processes is evident in the SCG (Hyatt-Sachs et al., 1990), while after organ culture, an increase in both immunoreactive cell bodies and nerve processes is seen (Zigmond et al., 1992; present results). Finally, the increase in VIP-IR after decentralization does not appear to be accompanied by an increase in VIP/PHI mRNA (H. Hyatt-Sachs and R. E. Zigmond, unpublished observations), while the increase after organ culture is accompanied by such a change. These findings raise the possibility that the change in VIP-IR after decentralization is not occurring primarily in postganglionic sympathetic neurons, but rather in a nonpreganglionic sympathetic afferent input.

\section{What triggers the increase in VIP-IR and substance P-IR in culture?}

The observations discussed above indicate that the lack of nerve firing in organ culture or short-term dissociated cultures of SCG does not cause the increase in either VIP- or substance-IR. Recent evidence suggests that axotomy of sympathetic neurons, which occurs when they are placed in culture, is an important factor in the stimulation of VIP expression. When the two major postganglionic trunks of the SCG are sectioned and the ganglion is left in situ, VIP-IR increases by 22 -fold and there is a large increase in the level of VIP/PHI mRNA (Hyatt-Sachs et al., unpublished observations). Interestingly, axotomy of sympathetic neurons has been reported not to altcr substance P-IR (Kessler and Black, 1982). One possible explanation for the effect of axotomy on VIP-IR and VIP/PHI mRNA is that certain autonomic target tissues contain a factor that normally inhibits VIP expression in sympathetic neurons in the SCG. This is in contrast to the explanation for the normal expression of VIP in a subset of neurons in the stellate and lower lumbar ganglia (Lundberg et al., 1979; Landis et al., 1988). In these ganglia, a target-derived factor in sweat glands has been proposed to stimulate VIP expression in those neurons that project to the glands (Stevens and Landis, 1988, 1990; Rao and Landis, 1990; Schotzinger and Landis, 1990b). While the identity of the VIP-inducing sweat gland factor is not yet known, two differentiation factors, ciliary neurotrophic factor (CNTF) and cholinergic dif- 
ferentiation factor (CDF)/leukemia inhibitory factor (LIF), stimulate VIP expression in cultured SCG neurons (Nawa and Patterson, 1990; Rao et al., 1992). Since target cells are not present in our organ culture experiments, however, the relevance of a target-derived stimulatory factor for the increase in VIPIR is unclear. Thus, if VIP-inducing factors, such as CNTF or $\mathrm{CDF} / \mathrm{LIF}$, are involved in the increased expression of VIP-IR in culture, they would have to be produced by cells in the ganglion itself, either the neurons or non-neuronal cells.

Not only do our results not support the hypothesis that a decrease in sympathetic nerve activity causes an increase in VIPor substance P-IR, either after decentralization or after explantation, they also provide evidence that increased nerve activity could actually increase the levels of these peptides. However, though it is often assumed that chronic depolarization mimics increased nerve activity, this may not be true for any particular physiological process (Zigmond and Bowers, 1981). Chronic depolarization mimics increased impulse activity poorly due to accommodation of time- and voltage-dependent ion channels, and it is unclear what type of change of nerve activity in terms of frequency, pattern, or duration would be equivalent to any particular paradigm of chronic depolarization. In addition, since many neurons release more than one transmitter, which act through more than one second messenger system, depolarization may mimic aspects of only one (or none) of these. A partial overlap may exist between the effects of depolarization and the effects of growth factors, like NGF, on the induction of immediate-early genes (Sheng and Greenberg, 1990). Given this overlap, an alternative interpretation of our data is that depolarization in vitro is activating a pathway for regulation of VIPIR that is activated in vivo by a neurotrophic factor.

It is possible that depolarization increases the expression of VIP-IR only in cultured or axotomized neurons and the expression of substance P-IR only in cultured neurons. Thus, the stimulation of the expression of these peptides by depolarizing agents may require their prior induction by other environmental factors. If this is in fact the case, our results on peptide expression, together with studies on the regulation of biogenic amine neurotransmitters, would support a more general hypothesis that depolarization increases the synthesis of whichever neurotransmitters a neuron is already producing.

\section{References}

Adler JE, Black IB (1984) Plasticity of substance P in mature and aged sympathetic neurons in culture. Science 225:1499-1500.

Agoston DV, Eiden LE, Brenneman DE, Gozes I (1991) Spontaneous electrical activity regulates vasoactive intestinal peptide expression in dissociated spinal cord cell cultures. Mol Brain Res 10:235-240.

Betz H, Changeux JP (1979) Regulation of muscle acetylcholine receptor synthesis in vitro by derivatives of cyclic nucleotides. Nature 278:749-752.

Black IB, Adler JE, La Gamma EF (1988) Neurotransmitter plasticity in the peripheral nervous system. In: Handbook of chemical neuroanatomy, Vol 6, The peripheral nervous system (Bjorklund A, Hokfelt T, Owman C, eds), pp 51-64. Amsterdam: Elsevier.

Chalazonitis A, Zigmond RE (1980) Effects of synaptic and antidromic stimulation on tyrosine hydroxylase activity in the rat superior cervical ganglion. J Physiol (Lond) 300:525-538.

Choi DW, Rothman SM (1990) The role of glutamate toxicity in hypoxic-ischemic neuronal death. Annu Rev Neurosci 13:171-182.

Coons AH (1958) Fluorescent antibody methods. In: General cytochemical methods (Danielli JF, ed), pp 399-422. New York: Academic.

Garcia-Arraras JE (1991) Modulation of neuropeptide expression in avian embryonic sympathetic cultures. Dev Brain Res 60:19-27.

Gurusinghe CJ, Bell C (1989) Substance P immunoreactivity in the superior cervical ganglia of normotensive and genetically hypertensive rats. J Auton Nerv Syst 27:249-256.

Hawrot E, Patterson PH (1979) Long-term culture of dissociated sympathetic neurons. Methods Enzymol 58:574-583.

Hayashi M, Edgar D, Thoenen H (1985) Nerve growth factor changes the ralive levels of neuropeptides in developing sensory and sympathetic ganglia of the chick embryo. Dev Biol 108:49-55.

Hefti F, Gnahn H, Schwab ME, Thoenen H (1982) Induction of tyrosine hydroxylase by nerve growth factor and by clevated $\mathrm{K}^{+}$concentrations in cultures of dissociated sympathetic neurons. J Neurosci 2:1554-1566.

Hokfelt T, Elfvin L-G, Schultzberg M, Fuxe K, Said SI, Mutt V, Goldstein $M$ (1977) Immunohistochemical evidence of vasoactive intestinal polypeptide-containing neurons and nerve fibers in sympathetic ganglia. Neuroscience $2: 885-896$.

Hyatt-Sachs H, Beinfeld MC, Baldwin C, Zigmond RE (1990) Vasoactive intestinal peptide (VIP) in the normal and decentralized superior cervical ganglion (SCG). Soc Neurosci Abstr 16:1029.

Ip NY, Perlman RL, Zigmond RE (1983) Transsynaptic regulation of tyrosine 3-monooxygenase activity in the rat superior cervical ganglion: evidence for both cholinergic and noncholinergic mechanisms. Proc Natl Acad Sci USA 80:2081-2085.

Johnson MI, Ross CD, Bunge RP (1980) Morphological and biochemical studies on the development of cholinergic properties in cultured sympathetic neurons. II. Dependence on postnatal age. J Cell Biol 84:692-704.

Kessler JA, Black IB (1982) Regulation of substance P in adult rat sympathetic ganglia. Brain Res 234:182-187.

Kessler JA, Adler JE, Bohn M, Black IB (1981) Substance $P$ in principal sympathetic neurons: regulation by impulse activity. Science 214:335-336.

Kessler JA, Adler JE, Bell WO, Black IB (1983) Substance P and somatostatin metabolism in sympathetic and special sensory ganglia in vitro. Neuroscience 9:309-318.

Koike T, Martin D, Johnson EM (1989) Role of $\mathrm{Ca}^{2+}$ channels in the ability of membrane depolarization to prevent neuronal death induced by trophic-factor deprivation: evidence that levels of internal $\mathrm{Ca}^{2+}$ determine nerve growth factor dependence of sympathetic ganglion cells. Proc Natl Acad Sci USA 86:6421-6425.

LaGamma EF, Adler JE, Black IB (1984) Impulse activity differentially regulates [leu]enkephalin and catecholamine characters in the adrenal medulla. Science 224:1102-1104.

Landis SC, Siegel RE, Schwab M (1988) Evidence for neurotransmitter plasticity in vivo. II. Immunocytochemical studies of rat sweat gland innervation during development. Dev Biol 126:129-140.

Lewis RV, Stern AS, Kilpatrick DL, Gerber LD, Rossier J, Stein S, Udenfriend S (1981) Marked increases in large enkephalin-containing polypeptides in the rat adrenal gland following denervation. $J$ Neurosci 1:80-82.

Lindh B, Lundberg J, Hokfelt T (1989) NPY-, galanin-, VIP/PHI-, CGRP- and substance P-immunoreactive neuronal subpopulations in cat autonomic and sensory ganglia and their projections. Cell Tissue Res 256:259-273.

Lundberg JM, Hokfelt T, Schultzberg M, Uvnas-Wallenstein K, Kohler C, Said SI (1979) Occurrence of vasoactive intestinal polypeptide (VIP)-like immunoreactivity in certain cholinergic neurons of the cat: evidence from combined immunohistochemistry and acetylcholinesterase staining. Neuroscience 4:1539-1559.

Nawa H, Patterson PH (1990) Separation and partial characterization of neuropeptide-inducing factors in heart cell conditioned medium. Neuron 4:269-277.

O'Lague PH, MacLeish PR, Nurse CA, Claude P, Furshpan EJ, Potter DD (1975) Physiological and morphological studies on developing sympathetic neurons in dissociated cell culture. Cold Spring Harbor Symp Quant Biol 40:399-407.

Otten U, Thoenen $H$ (1976) Mechanisms of tyrosine hydroxylase and dopamine $\beta$-hydroxylase induction in organ cultures of rat sympathetic ganglia by potassium depolarization and cholinomimetics. Naunyn Schmiedebergs Arch Pharmacol 292:153-159.

Pattcrson PH, Chun LLY (1977) The induction of acetylcholine synthesis in primary cultures of dissociated rat sympathetic neurons. II. Developmental aspects. Dev Biol 60:473-481.

Potter DD, Landis SC, Matsumoto SG, Furshpan EJ (1986) Synaptic functions in rat sympathetic neurons in microcultures. II. Adrenergic/ cholinergic dual status and plasticity. J Neurosci 6:1080-1096. 
Kaisman G, Field PM, Ostberg AJC, Iversen LL, Zigmond RE (1974) A quantitative ultrastructural and biochemical analysis of the process of reinnervation of the superior cervical ganglion in the adult rat. Brain Res 71:1-16.

Rao MS, Landis SC (1990) Characterization of a target-derived neuronal cholinergic differentiation factor. Neuron 5:899-910.

Rao MS, Tyrrell S, Landis SC, Patterson PH (1992) Effects of ciliary neurotrophic factor (CNTF) and depolarization on neuropeptide expression in cultured sympathetic neurons. Dev Biol 150:281-293.

Rittenhouse AR, Schwarzschild MA, Zigmond RE (1988) Both synaptic and antidromic stimulation of neurons in the rat superior cervical ganglion acutely increase tyrosine hydroxylase activity. Neuroscience 25:207-215.

Robinson SE, Schwartz JP, Costa E (1980) Substance P in the superior cervical ganglion and the submaxillary gland of the rat. Brain Res 182:11-17.

Salpeter MM, Kasprzak H, Feng H, Fertuck H (1979) Endplates after esterase inactivation in vivo: correlation between esterase concentration, functional response and fine structure. J Neurocytol 8:95-111.

Sasek CA, Zigmond RE (1989) Localization of vasoactive intestinal peptide- and peptide histidine isoleucine amide-like immunoreactivities in the rat superior cervical ganglion and its nerve trunks. J Comp Neurol 280:522-532.

Schotzinger RJ, Landis SC (1990a) Postnatal development of autonomic and sensory innervation of thoracic hairy skin in the rat. A histochemical, immunocytochemical, and radioenzymatic study. Cell Tissue Res 260:575-587.

Schotzinger RJ, Landis SC (1990b) Acquisition of cholinergic and peptidergic properties by sympathetic innervation of rat sweat glands requires interaction with normal target. Neuron 5:91-100.

Schulzberg M, Lundberg JM, Hokfelt T, Brandt J, Elde RP, Goldstein M (1978) Enkephalin-like immunoreactivity in gland cells and nerve terminals of the adrenal medulla. Neuroscience 3:1169-1186.
Sheng M, Greenberg ME (1990) The regulation and function of c-fos and other immediate early genes in the nervous system. Neuron 4 $477-485$.

Skok VI (1973) Physiology of autonomic ganglia, p 139. Tokyo: Igaku Shoin.

Stevens LM, Landis SC (1988) Developmental interactions between sweat glands and the sympathetic neurons which innervate them: effects of delayed innervation on neurotransmitter plasticity and gland innervation. Dev Biol 130:703-720.

Stevens LM, Landis SC (1990) Target influences on transmitter choice by sympathetic neurons developing in the anterior chamber of the eye. Dev Biol 137:109-124

Wakade AR, Thoenen H (1984) Interchangability of nerve growth factor and high potassium in the long-term survival of chick sympathetic neurons in serum-free culture medium. Neurosci Lett 45:7174.

Walicke PA, Campenot RB, Patterson BA (1977) Determination of transmitter function by neuronal activity. Proc Natl Acad Sci USA 74:5767-5771.

7igmond RF, Bowers CW (1981) Influence of nerve activity on the macromolecular content of neurons and their effector organs. Annu Rev Physiol 43:673-687.

Zigmond RE, Mackay AVP (1974) Dissociation of stimulatory and synthetic phases in the induction of tyrosine hydroxylase. Nature 247: $112-113$.

Zigmond RE, Schwarzschild MA, Rittenhouse AR (1989) Acule regulation of tyrosine hydroxylase by nerve activity and by neurotransmitters via phosphorylation. Annu Rev Neurosci 12:415-461.

Zigmond RE, Hyatt-Sachs $\mathrm{H}$, Baldwin C, Qu XM, Sun Y, McKeon TW, Schreiber RC, Vaidyanathan U (1992) Phenotypic plasticity in adult sympathetic neurons: changes in neuropeptide expression in organ culture. Proc Natl Acad Sci USA 89:1507-1511. 